\title{
Fengslenes innsats overfor innsatte med rusproblemer: ansattes perspektiv
}

\author{
Af Hedda Giertsen ${ }^{1}$ og Torsten Kolind ${ }^{2}$
}

\begin{abstract}
Denmark, Finland, Norway and Sweden are similar in many respects. But as Hakkarainen et al. (2006) noted in regard to Nordic drug policies twenty years ago, "sisters are never alike». This saying also applies to drug policies in the Nordic prison systems.

As part of a common project comparing drug policies across the Nordic prison systems, the following four articles describe staff experiences with measures aimed at prisoners with drug problems. Staff consists of both prison officers and counsellors, who by and large perform different tasks. Prison officers concentrate on security and control while counsellors tend to focus on programs and group sessions. The boundaries between these roles are, however, sometimes blurred.

All four articles apply a relational perspective to staff experiences in the prison environment. But they also apply different approaches, and various results appear. The Finnish article finds the staff to be influenced very little by the programs and prison environment while the Swedish article finds just the opposite. The Danish article presents a staff typology that describes modes of adjustment to the prison. Meanwhile, the Norwegian article investigates how various actors within the system cooperate and handle conflicts. Differences are also demonstrated in regard to staff views on the implications of control and the use of sanctions in the programs.

Drug treatment measures are organized in different ways in the Nordic systems depending on the way counsellors are employed and the degree of cooperation the prison has with the national health and welfare services. The editorial discusses the relationship between organization and perceptions of drug problems.

Prison measures toward drug problems can be seen as a prism that refracts diversity in prison policies and variations between the Nordic countries. In some countries, such measures are seen as contributing to the general prison drug policy, while in other countries the public health and welfare services are in focus. *

* Title in English: Prison staff perspectives on measures aimed at inmates with drug problems.
\end{abstract}


Fire nordiske land, Danmark, Finland, Norge og Sverige ligger nær hverandre geografisk og er på mange måter like, særlig sett fra andre steder i verden. Og likevel, Sisters are never alike, skrev Hakkarinen m.fl. (1996) nettopp om de nordiske landene og deres ruspolitikk. Slik er det også, når det gjelder tilbud for innsatte med rusproblemer, som er vårt tema her. I fengsler i de nordiske land var det i 2012 opprettet behandlings- og rehabiliteringsprogram med ett til to møter hver uke over noen måneder. Det er også opprettet egne avdelinger med døgntilbud. Antall plasser i slike døgnavdelinger utgiør mellom 5 og 12 prosent av alle fengselsplasser. ${ }^{3}$

Denne lederen og de fire følgende artiklene er del av et nordisk prosjekt om tilbud for innsatte med rusproblemer i Danmark, Finland, Norge og Sverige. ${ }^{4}$ I prosjektets første del ble tilbud til innsatte med rusproblemer beskrevet med grunnlag i synspunkter fra politisk og administrativ ledelse, hentet fra intervjuer og dokumenter. ${ }^{5}$ Her i prosjektets annen del beskrives slike tilbud med grunnlag i ansattes erfaringer; og i tredje og kommende del med grunnlag i innsattes erfaringer. Prosjektet omfatter tre tilbud til innsatte med rusproblemer i tre fengsler $\mathrm{i}$ hvert av de fire landene.

Ansatte er en viktig part i beskrivelsen av rusmestringsavdelinger. De formidler myndighetenes fengselspolitikk og ruspolitikk i fengsel. Det er de ansatte som gjennom sine forståelser, vurderinger, væremåter og avgjørelser konkretiserer og utformer politikken overfor innsatte i rusmestringsavdelingene mens de er på jobb, og skal håndtere ulike typer situasjoner, dilemmaer og utfordringer. De ansatte står mellom myndigheter og innsatte, strukturelt sett. Derfor er også deres erfaringer vesentlige når rusmestringsavdelinger og program skal beskrives.

Rustilbud i fengsel opptrer ikke isolert, men er formet av de fire landenes fengsels- og ruspolitikk. Vi åpner med en kort oversikt over noen hovedtrekk i dette landskapet. Det handler både om trekk som forener de nordiske landene og om ulikheter landene imellom.

Tallene for innsatte er lave i de fire nordiske landene sammenliknet med de fleste andre land. Men det er også noen forskjeller: I 2013 varierte disse tallene landene mellom 3100 i Finland og 6400 i Sverige (ICPS 2014). Tallene omfatter soning og varetekt. Det relative antall fanger varierte mellom 58 pr. $100.000 \mathrm{i}$ Finland, og 73 pr. 100.000 i Danmark.

Også når det kommer til materiell standard er nordiske fengsler på flere måter eksepsjonelle. På disse punktene utgjør de fire landene en Nordic exceptionalism (Pratt 2008 a, b). ${ }^{6}$

De nordiske landene er forskjellige når det gjelder bruk av fengsel for narkotikalovbrudd. Finland med 15 prosent innsatte som soner for narkotikalovbrudd 
ligger på linje med Nederland, Tyskland og Storbritannia, mens Danmark, Norge og Sverige med mellom 21 og 28 prosent, bruker fengsel i større grad overfor mennesker med rusproblemer, og er på linje med Spania, Sveits og Portugal (Council of Europe 2012:94). Slike variasjoner i andelen innsatte som soner for narkotikalovbrudd sier ikke noe om narkotikaproblemets omfang i de ulike landene, men om i hvilken grad myndigheter anser fengsel som egnet for å løse de problemene en god del rusbruk fører med seg, og om den betydning fengsel tillegges i narkotikapolitisk sammenheng.

Som i andre land er fengselspolitikk i Norden todelt og speiler det dobbelte, til dels motsetningsfylte målet om straff og rehabilitering. ${ }^{7}$ Også i Norden blir innsatte isolert og det skjer brudd med internasjonale konvensjoner (CPT 1993-2011, Smith 2012). I to av landene, Danmark og Norge har det skjedd en øking i antall innsatte fra 1990-tallet til i dag. Det er ingen slik tydelig linje i Finland (ICPS 2014), og i Sverige er fangetallet gått ned i senere år (ibid.)

I fengslenes innsatser overfor rusbrukere møtes kontroll/straff og helse- og sosiale tjenester; det vil si fengselspolitikk, ruspolitikk, helse- og sosialpolitikk. På disse områdene er det variasjoner de fire landene imellom, og det er variasjoner fengsler og tilbud imellom. Dette er rammene de ansatte arbeider innenfor når de utformer sine roller og oppgaver stilt overfor dilemmaer og problemer.

Datagrunnlaget i de fire artiklene er de ansattes erfaringer fra ulike innsatser mot rusbruk i 12 nordiske fengsler, tre i hvert land. Av disse innsatser er åtte strukturerte forløp som minner om døgnbehandling utenfor fengslene, og fire tilbud kan sammenliknes med ambulant behandling med møter en eller et par ganger i uka, i perioder på noen måneder.

I alle fire land var tilbudene valgt ut slik at ett av dem var for kvinner. Gruppen ansatte som ble intervjuet omfatter direktører, inspektører og betjenter som har ansvar for fengslets daglige drift når det gjelder sikkerhet. Og det er ansatte som arbeider med bestemte program og opplegg overfor fanger med rusproblemer, disse ansatte har sosialfaglig utdanning eller korte kurs. Ettersom behandlerne i de 12 fengslene er tilknyttet fengslet på forskjellige måter og ettersom betjentenes roller $\mathrm{i}$ forhold til behandlingen også varierer, er det benyttet litt forskjellige utvalgsstrategier. Stort sett er alle behandlere og betjenter som er involvert i behandling blitt intervjuet på de avdelingene og i de behandlingstiltak som studien undersøkte. Utvalget av betjenter uten behandlingsansvar er foretatt utfra hvem som hadde arbeidet en stund i avdelingen og hvem av dem som ønsket å delta. De intervjuete betjentene dekker dermed ikke alle betjenter. I alt er 104 ansatte blitt intervjuet.

I tillegg er det foretatt tilsammen seks måneders feltstudier i de 12 fengslene. Det ble brukt samme intervju- og observasjonsguide i alle land, og de hadde også 
plass til spørsmål og temaer av særskilt nasjonal relevans. Intervjuguidene var rettet mot programmenes rasjonale og mål, den intervjuetes vurdering av den innsattes primære problemer, kontroll og disiplinærsanksjoner sett i forhold til ulovlig rusbruk; og også roller og relasjoner ansatte imellom. Observasjonsguidene fokuserte på selve behandlingsmiljøet, personlige relasjoner og daglige rutiner, prosedyrer og kontrolltiltak av betydning for gjennomføringen av programmene. For mer uførlige metodeoverveielser henvises det til de enkelte artiklene.

Hvilke temaer og diskusjoner som tas opp i de fire nasjonale artiklene varierer, for her speiles ulike fagbakgrunner, fagtradisjoner og perspektiver, samt ulike faktiske forhold i de fire landene.

Alle artiklene tar i bruk et relasjonelt perspektiv og ser ansattes beskrivelser av sine oppgaver og roller, konflikter og dilemmaer i forhold til trekk ved fengslene; og ved tilbud og program.

Den danske artikkelen lager en typologi over ansattroller. Her beskrives to utforminger av behandlerrollen: forandringsarbejderen og den opsøgende gademedarbejder og to utforminger av betjentrollen: behandlerens forlengede arm og den pragmatiske betjent. De fire utformingene sees relasjonelt i forhold til type fengsel og hvilke rusbehandlingsopplegg som tilbys. Også i den svenske og finske artikkelen sees utformingen av rolle i forhold til type fengsel og opplegg for innsatte. Den finske undersøkelsen fant at rolleutformingen for sosialfaglig ansatte var lite påvirket av type fengsel og program, og at rollen for betjenter og sosialfaglig ansatte var overraskende fleksible. Den svenske undersøkelsen fant at fengslets utforming og rammer, så vel som program, får betydning for hvordan betjenter ser på rus, rusbehandling og identitet. I den norske artikkelen handler typologien om de sosiale rommene som oppstår: det fengselsmessige og det sosialfaglige, og her beskrives hvordan de to profesjonene deler tid og rom, samarbeider og håndterer konflikter. Tanken er å belyse hvordan ansatte og innsatte ser hverandre og hva som blir vesentlig, i slike rusmestringsavdelinger.

Det er ulike forståelser av hva rusproblemer er og hva som er en relevant og god tilnærming i de fire landene: I Danmark sees rusproblemer primært som et individuelt anliggende, hvor behandlingens mål er å finne tilbake til ens 'egentlige, rusfrie jeg'. I Danmark, Finland og Sverige og noe i Norge brukes 12-trinns- og AA-program hvor rusproblem i stor grad sees som sykdom. Å bli rusfri sees her som et individuelt prosjekt som håndteres med hjelp av grupper. I alle fire land, men i ulik grad, brukes også kognitive program, motiverende intervju og terapeutiske samfunn. Nå sees rusproblem mer som uegnet atferd, og grupper med vekt på 'fellesskap som metode' som vesentlig for å endre slik atferd. Rusbruk koples også til levekår og miljø, det siste er sentralt i senere års norske fengselspolitikk 
(st.meld. nr. 37 (2007-2008)). Ulike tilbud i fengslene, og deres forståelser av hva rusproblemer er, viser noe av den variasjonen som fins i samfunnet. Men, som man kan vente, er skadereduksjonstiltak knapt nok til stede i fengslene.

Det er forskjellig hva rustilbud kalles i de fire landene, behandling i Sverige, Finland og Danmark, motivering og rehabilitering i Norge. Selve innholdet i de ulike typene tilbud kan nok ha likhetstrekk i alle fire land, men hva det kalles og betydningen det gis, vil gi ulik fengsels- og narkotikapolitisk betydning.

Rustilbud organiseres ulikt i de fire nordiske landenes fengsler. Betjenter, inspektører og direktører er ansatt av fengselsmyndighetene. Dette er likt i de fire landene. Men hvem som ansetter sosialfaglig personale i behandlings- og rehabiliteringsprogrammene varierer. I Sverige og Finland er også denne gruppen i hovedsak ansatt av fengselsmyndighetene, i Norge og Danmark oftest av andre myndigheter i overensstemmelse med importmodellen (Christie 1973/1993). Men det er likevel en forskjell. I Danmark blir institusjoner som ivaretar rusbehandlingen utenfor fengslet betalt av fengslene for å arbeide i fengslet. Det kan være kommunale myndigheter eller selveiende private organisasjoner. I Norge er det den myndighet som har ansvar for bestemte oppgaver ute i samfunnet som skole-, helse- og sosialfaglige tjenester, som også ansetter og lønner fagpersoner til å arbeide i fengslet. Dette er overveiende offentlige myndigheter, kommunale og statlige.

Det kan se ut som oppfatningen av hva rusproblemet er og hvordan det skal løses, preges av hvordan rustilbudene organiseres: Når organisasjonen som utformer ruspolitikken ikke har en tett og nær tilgang til og rutiner for å aktivisere det offentlige hjelpeapparatet, er det en tendens til at den enkeltes rusproblem individualiseres. I de norske rushjelpsavdelingene som er preget av tilbakeføringsgarantien (KSF 2011), koples innsatte til kommunale og statlige helse- og sosialtjenester, og rusproblemer sees i større grad i sammenheng med de livsvilkår en person har. Slik sett kan vi si med Jöhncke: Treatment is the solution that defines our knowledge of the problem (Jöhncke 2009:17), svaret definerer problemet, sier også Nesvåg (2011).

En annen interessant side det fortelles om, er felles for de fire landene. Ansatte ser det som viktig å gjøre noe for innsatte mens de soner, slik det har vært siden begynnelsen av 1900-tallet. Det er full enighet om at når innsatte har rusproblemer, bør man gjøre noe for å bedre deres situasjon. Ansatte forteller med entusiasme om sine erfaringer; problemer og dilemmaer blir nevnt av noen, men optimismen dominerer, også slik at de fleste ansatte ikke ser koblingen mellom kontroll-sanksjoner og behandlings- eller motivasjonstilbud som noe problem, men noen gjør det. Dette er et interessant funn. Her fins det variasjoner og ulike synspunkter blant ansatte. Ett synspunkt ser urinprøver som et nyttig hjelpemiddel, 
fordi det gir grunnlag for å ta opp eventuell ulovlig rusbruk; et annet går ut på at slike kontroller ikke er nødvendige. I en liten avdeling vil ansatte og ikke minst andre innsatte merke om noen bruker rusmidler. Når det gjelder synspunkter på urinprøve som brudd på den enkeltes integritet, gir ansatte inntrykk av å se dette som et lite problem. Derimot ble andre kontroller og sanksjoner sett som inngripende, som razzia i norske fengsler.

Det er også eksempel på at sosialfaglige ser isolasjon i et nytteperspektiv, som effektive for å kunne avskrekke andre (i et allmennpreventivt perspektiv), ${ }^{8}$ og også føre til at den som sperres inne tenker over sin egen rusbruk. Denne sanksjonens sterkt nedbrytende virkning (Hellevik 2001, Smith m. fl. 2014) reiser grunnleggende etiske spørsmål, og også om rettssikkerhet, som prinsippet om forholdsmessighet.

Enda et standpunkt blant ansatte er at hensyn til kontroll og sikkerhet, fengselsreglement og rutiner hindrer rusmestringsavdelingene $i$ å følge opp og gi den enkelte fange mulighet til å prøve nye utfordringer. Slik er det også når en innsatt har brutt en regel, en sosialfaglig vurdering vil gå ut på om den innsatte trenger mer støtte, oppmuntring og nye muligheter; mens fengselsregime tilsier det motsatte, mer kontroll, sanksjoner og restriksjoner. Dette tilsvarer tidligere tiders erfaringer med forsøk på å kombinere fengsel og opplæring, psykiatrisk behandling eller alkoholproblemer (Giertsen 2012).

Den svenske rapporten forteller om ulike holdninger til kontroll. I et stort fengsel med vekt på sikkerhet, er relasjonen mellom ansatte og innsatte preget av en distansert kultur. Ansatte $\mathrm{i}$ to mindre fengsler legger mer vekt på dynamisk sikkerhet og deres relasjon til innsatte er preget av en «nærhetens kultur».

Enda et felles funn i de fire landene er at andre innsatte og en del ansatte i andre, vanlige avdelinger ser soning i avdelinger for innsatte med rusproblemer som lett og enkel, vaffelsoning, blir det kalt i Norge. Men en erfaringer blant ansatte er at soning i slike avdelinger er uvant og krevende: «Å dele litt av sjela si i en gruppe med andre mannfolk, det gjør man ikke frivillig, men fordi man må» (S9, Norge).

Avdelinger for innsatte med rusproblemer kan sees som et prisme som spektrer ulike sider ved fengsels- og narkotikapolitikken. Gjennom de fire artiklene ser vi ulike bidrag til diskusjoner om nulltoleranse og narkotikafritt miljø; betydning av kontroll og straff som del av hjelpetilbud. Her er ulik vekt på hva som hender med dem som ikke lykkes i opplegget og sendes tilbake til vanlig fengselsavdeling. Og det er ulik vekt på betydningen av fengsel som sted for å foreta behandling, eller forberedelse og motivering til behandling etter soning, og som del av dette, ulike syn på bruk av begrepene behandling eller rehabilitering/motivering. 
Det er også tydelig at ansatte ser at innsatte ikke bare har rusproblemer. Et standpunkt er at innsatte kan være avhengige av spenningen i å begå lovbrudd, eller de har en truende væremåte. Ansatte ser også at innsatte trenger sosialhjelp og helsehjelp og hjelp til å (gjen)opprette sosiale bånd. Det er ett trekk ved fengslene som går igjen over tid og mellom land: de henter gjennomgående og tendensielt sine rekrutter blant de fattige i en befolkning, slike som er fattige langs flere dimensjoner: materielt, og i forhold til kapitaler slik Bourdieu (1999) definerer dem, når det gjelder helse og sosiale bånd (Friestad og Hansen 2004). Rusbrukere er ikke noe unntak, tvert om (i Norge, Thorsen 2001). Kriminalisering av bruk, besittelse og småomsetting av narkotika har bidratt til å øke fangetall generelt og antall fattige i fengsel spesielt (Christie 2000, Wacquant 1999, 2009, Stene 2008, Houborg \& Pedersen 2013).

De fire artiklene skriver seg inn i en diskusjon om hvilken plass fengslene har og bør ha i fengsels- og narkotikapolitisk sammenheng. Og de skriver om hvordan de nordiske landenes politikk på dette området viser at «sisters are never alike» (Hakkarinen m.fl. 1996). I noen land sees narkotikatilbud i fengslene som et viktig bidrag til narkotikapolitikken. I andre land tones fengslets betydning ned, til fordel for det vanlige helse- og sosialvesenets betydning også overfor innsatte.

\section{Noter}

1. Hedda Giertsen er professor i kriminologi ved Institutt for kriminologi og rettssosiologi, Universitetet i Oslo og har i senere tid arbeidet med spørsmål om fengsel og rus.

2. Torsten Kolind er ph.d. i antropologi og ansatt som lektor ved Center for Rusmiddelforskning, Aarhus Universitet. Hans forskningsområder inkluderer bl.a. stoffbehandling og narkotikakontroll i fengsler, og unge og alkohol. Endvidere er han studieleder på den europeiske Master i narkotika- og alkoholindsatser, og redaktør for tidsskriftet Drugs: education, prevention and policy.

3. Omfang av program beskrives på ulike måter. I Danmark beregnes 10 til 20 prosent av alle fanger å være med i et tilbud for rusproblemer, mens 12 prosent beregnes å være med i et døgntibud (Kolind et al. 2012). I Finland var det i 2012 seks rusbehandlingsprogram hvor 311 innsatte deltok (Tourunen og Kaskela, 2014). I Norge tilbys ambulant program for fanger fra forskjellige avdelinger, og i første halvdel av 2012 ble 180 deltakelser i slike program avsluttet (Ploeg i Giertsen 2012). Døgnplasser for fanger med rusproblem utgjør $5 \%$ av alle fangeplasser $(\mathrm{N}=3800)$ (ibid.). I Sverige var det i 2012960 behandlingsplasser for rusbrukere i svenske fengsler, og i alt var det ca. 5000 soningsplasser (Holm et al., 2014) og 6500 sonings- og varetektsplasser (häkte) (ICPS 2014).

4. Takk til Nordisk Samarbejdsnævn for Humanistisk og Samfundsvidenskabelig Forskning (NOS-HS), som har bidratt til å finansiere dette prosjektet

5. Giertsen 2012, Kolind et al. 2012, Nylander et al. 2012, Tourunen et al. 2012. 
6. Pratt kaller det Scandinavian exceptionalism, til tross for at han har med Finland og utelater Danmark. Vi kaller det Nordic exceptionalism fordi vårt prosjekt omfatter fire nordiske land.

7. Danmark: Kriminalforsorgens Principprogram, september 1993. Finland: Rikosseuraamuslaitoksen strategia 2011-2020 (The strategy of Criminal Sanctions Agency for the years 20112020). Norge: straffegjennomføringslovens $\S 2$, jf ot.prp. nr. 90 (2003-2004); Sverige: Förordning (2007:1172) med instruktion för Kriminalvården (Svensk författningssamling 2007).

8. Dette reiser den ofte nevnte innvendingen mot allmennpreventiv avskrekking, at det er uetisk å bruke straffe et menneske med den begrunnelsen at det skal påvirke andre, og dermed bruke ham eller henne som et middel.

\section{Litteratur}

Bourdieu, P. (1999). Meditasjoner. Oslo: Pax forlag

Christie, N. (1973/1993). Modeller for fengselsorganisasjonen. I T. Mathiesen \& A. Heli (red). Murer og mennesker (s. 113-120). Oslo: Pax forlag.

Christie, N. (2000). Kriminalitetskontroll som industri: mot GULAG, vestlig type. Oslo: Universitetsforlaget.

Council of Europe. Annual Penal Statistics. Space 1 survey 2010. (2012). Marcelo F.A. \& Delgrade, N. Strasbourg: Council of Europe.

CPT (European Committee for the Prevention of Torture and Inhuman or Degrading Treatment or Punishment) Norway. Hentet fra www.cpt.coe.int/en/states/nor.htm.

Friestad, C. \& Hansen, I.L.S. (2004). Levekår blant innsatte. FAFO-rapport 429. Oslo: FAFO.

Förordning (2007) med instruktion för Kriminalvården (Svensk författningssamling 2007). http://www.riksdagen.se/sv/Dokument-Lagar/Lagar/Svenskforfattningssamling/Forordning20071172-med-ins_sfs-2007-1172/

Giertsen, H. (2012). Increased control, answers to poverties and looking for a life after release. Nordic Studies on Alcohol and Drugs årg. 29 (6): 589-604.

Hakkarainen, P., Laursen, L. \& Tigerstedt, C. (1996). Introduction: Sisters are never alike. I P. Hakkarainen, L. Laursen \& C. Tigerstedt (red.), Discussing drugs and control policy. Comparative studies on four Nordic countries. NAD Publication no. 31. Helsinki: NAD.

Hellevik, V. (2001). Bruk av isolasjon i norske fengsler. (JussBuss. Institutt for kriminologi og rettssosiologi. Stensilserien JussBuss, nr. 84.) Oslo: Universitetet i Oslo.

Holm, C. et al. (2014). Flera nyanser av blått. Kriminalvårdare på behandlingsavdelningar - deras beskrivningar av yrkesroller, drogbehandling och de intagna. Nordisk Tidsskrift for Kriminalvidenskab 2/2014.

Houborg, E. \& Pedersen, M.M. (2013): Håndhævelse af narkotikalovgivningen vedr. besiddelse af illegale stoffer til eget forbrug efter 2004. Aarhus: Center for Rusmiddelforskning, Aarhus Universitet.

ICPS (International Centre for Prison Studies) (2013). World Prison Brief. (besøkt 08.04.2014). http://www.prisonstudies.org/info/worldbrief/?search=europe\&x=Europe

Jöhncke, S. (2009). Treatmentality and the governing of drug use. Drugs and Alcohol Today årg. 9, (4): 14-17.

Kolind, T., Asmussen Frank, V., Dahl, H.V., \& Haller, M. (2012). Prison drug treatment in Denmark: A historical outline and an analysis of the political debate. NAD Nordic Studies on Alcohol and Drugs årg. 29 (6): 547-560. 
Kriminalforsorgens Principprogram (1998). København: Direktoratet for kriminalforsorgen. file://Users/hedda/Downloads/Principprogram.pdf

KSF (Kriminalomsorgens sentrale forvaltning) (2011). Tilbakeføringsgarantien. I Smått \& Stort, nr. 2-2011. Oslo: Justis- og beredskapsdepartementet.

Nesvåg, S. (2011). Muntlig innlegg om boka 'Mennesket bak rusen'. 2.11.2011, Oslo: Litteraturhuset.

Nylander, P.Å., Holm, C., Jukic, E. \& Lindberg, O. (2012). Drug treatment in Swedish prisons moving towards evidence-based interventions? NAD Nordic Studies on Alcohol and Drugs årg. 29 (6): 561-574.

Ot.prp. $n r .90$ (2003-2004) Om lov om straff (straffeloevn). Oslo: Justis- og beredskapsdepartementet. http://www.regjeringen.no/nb/dep/jd/dok/regpubl/otprp/20032004/otprp-nr-90-20032004-.html?id=179300

Pratt, J. (2008a). Scandinavian exceptionalism in an era of penal excess. Part I: The nature and roots of Scandinavian exceptionalism. British Journal of Criminology årg. 48, (2): 119-137.

Pratt, J. (2008b). Scandinavian exceptionalism in an era of penal excess. Part II: Does Scandinavian exceptionalism have a future? British Journal of Criminology årg. 48, (3): 275-292.

Rikosseuraamuslaitoksen strategia 2011-2020 (The strategy of Criminal Sanctions Agency for the years 2011-2020). (2011). Helsinki: Rikosseuraamuslaitos.

Smith, P.S. (2012). A critical look at Scandinavian exceptionalism: welfare state theory, penal populism and prison conditions in Denmark and Scandinavia. I T. Ugelvik \& J. Dullum (red.) Penal exceptionalism? Nordic prison policy and practice. London and New York: Routledge.

Smith, P.S. m.fl. (2014). Isolation i skandinaviske fængsler. I Social Kritik tidsskrift for social analyse og debatt, vol. 25 (136): 4-20.

St.meld. nr. 37 Straff som virker - mindre kriminalitet - tryggere samfunn (kriminalomsorgsmelding) (2007-2008). Oslo: Justis- og politidepartementet.

Stene, R.J. (2008). Narkotikasiktedes lovbrudd preger rettssystemet. Samfunnsspeilet årg. 22 (1): 5-17. http://brage.bibsys.no/ssb/handle/URN:NBN:no-bibsys_brage_15752

Svensk författningssamling (2007). Förordning (2007:1 172) med instruktion för kriminalvården. Besøkt 30.9.2013. Hentet fra: http://www.riksdagen.se/sv/Dokument-Lagar/Lagar/ Svenskforfattningssamling/Forordning-20071172-med-ins_sfs-2007-1172/

Straffegjennomføringsloven. Lov om gjennomføring av straff. LOV-2001-05-18-21. http://lovdata.no/dokument/NL/lov/2001-05-18-21

Thorsen, L. (2004): Kriminalisering av fattige: levekårssituasjonen blant straffede for narkotikalovbrudd I: Arsrapport 2003. Institutt for kriminologi og rettssosiologi. Oslo: Universitet i Oslo.

Tourunen, J. Weckroth, A. \& Kaskela, T. (2012). Prison-based drug treatment in Finland: History, shifts in policy making and current status. NAD Nordic Studies on Alcohol and Drugs årg. 29 (6): 575-588.

Tourunen, J. \& Kaskela, T. (2014). «Give them a chance!» The social representation of the counselor's institutional role in prison-based drug treatment programs in Finland. Nordisk tidsskrift for kriminalvidenskab 2/2014.

Wacquant, L. (1999). Fattigdommens foengsler. København: Socialpolitiskt forlag.

Wacquant, L. (2009). Punishing the poor. The Neo-liberal Government of Social Insecurity. Durham: Duke University Press. 